\title{
FILOSOFÍA, RETÓRICA Y ARGUMENTACIÓN EN LA INDIA
}

\author{
Philosophy, rhetoric and argument in India
}

\author{
Roberto Morales Harley*
}

\begin{abstract}
RESUMEN
El trabajo sostiene que filosofía, retórica y argumentación, campos de estudio tradicionalmente considerados occidentales, existieron en la India. Darśana (punto de vista), en su multiplicidad de corrientes, se ocupa de la filosofía; la unión entre nyāya (lógica) y alan்kāras (figuras retóricas) resulta en una retórica sui generis; y las diversas modalidades de kathā (discusión) ofrecen un espacio apropiado para la argumentación. No obstante, los conceptos se traslapan. Finalmente, se incluyen algunos ejemplos del Mahābhārata.

Palabras clave: filosofía india, retórica india, argumentación india, épica india.
\end{abstract}

\section{ABSTRACT}

The paper states that Philosophy, Rhetoric, and Argumentation, traditionally considered Western fields of study, did exist in India. Darśana (point of view), through its multiple currents, deals with Philosophy; the juncture between nyāya (logic) and alainkāras (figures of speech) results in a sui generis Rhetoric; and the diverse modes of kathā (discussion) offer an appropriate environment for Argumentation. Nonetheless, the concepts overlap. In the end, some examples driven from the Mahäbhārata are included.

Key Words: Indian Philosophy, Indian Rhetoric, Indian Argumentation, Indian Epics.

Universidad de Costa Rica, Profesor, Escuela de Filología, Lingüística y Literatura. Costa Rica Correo electrónico: roberto.moralesharley@gmail.com

Recepción: 14/4/2016. Aceptación: 20/4/2016. 
Sólo desde las costas mediterráneas las lenguas europeas pueden acercarse a las orillas del Ganges (Panikkar, 2000: 17).

Occidente está representado por la teoría o gnôsis y

Oriente por la praxis o karma (Panikkar, 2000: 14).

\section{Introducción}

Filosofía, retórica y argumentación son todos conceptos propios de la tradición greco-latina. La presente propuesta parte de dos premisas fundamentales, directamente relacionadas con sendos epígrafes incluidos al inicio del trabajo: por una parte, el hecho de que los conceptos utilizados para referirse a los ámbitos en cuestión (filosofía, retórica y argumentación) no existan en lengua sánscrita no implica que las disciplinas a que estos remiten estén ausentes en la cultura y en la literatura sánscrita; por otra parte, el hecho de que no todos los temas cuenten con formulaciones teóricas no implica que estos no hayan sido objeto de un desarrollo práctico, ya en textos literarios, ya en otros espacios.

De lo anterior, se colige que, para poder entablar cualquier tipo de diálogo entre la tradición filosófica, retórica o argumentativa greco-latina, por un lado, y la sánscrita, por otro, es preciso partir de los términos en sus respectivos idiomas, con la intención de, posteriormente, analizar su presencia en los textos literarios.

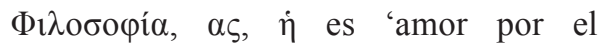
conocimiento', 'indagación', 'estudio o práctica de un arte o de una ciencia', 'ciencia', 'cultura intelectual'; 'cultivo metódico de un arte', 'estudio científico de la argumentación'; 'indagación sobre la esencia de las cosas', 'estudio de las cosas de la naturaleza', 'búsqueda de la verdad', 'filosofía' (Bailly, 2000: 2079-2080). Este término, pasa al latín como philosophia, -ae, f., 'filosofía'; 'doctrina o escuelas filosóficas'; y, al español, como filosofía, hacia 1250 (Segura, 2003: 564).

Por su parte, $\dot{\rho} \eta \tau$

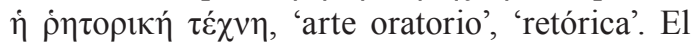

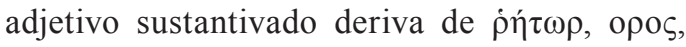
$\dot{o}$, $\dot{\eta}$, que primero significa 'orador público' y después adquiere el sentido de 'maestro de retórica' (López, 1998: 62). Este, a su vez, proviene de la raíz indoeuropea werz- ${ }^{3}$, 'hablar', la cual da origen al inglés word, al alemán Wort, al latín verbum, al griego $\dot{\eta} \tilde{\mu} \alpha$ (Watkins, 2000: 100). En latín, coexisten las formas rhetorica, -ae, $f$. y rhetorice, -ces, $f$., 'retórica'; $\mathrm{y}$, en español, la forma retórica se encuentra registrada por primera vez, igualmente, hacia 1250 (Segura, 2003: 666).

Por último, el español argumentación se remonta, no al griego, sino al latín. Argumentatio, -onis, $f$., 'argumentación', 'argumentos' viene de argumentor, -ari, -atus sum, 'argumentar', 'discutir', 'aportar pruebas'; 'presentar como prueba', 'argüir'. Este verbo, a su vez, procede de argumentum, - $i$, n., 'argumento', 'prueba', 'razón convincente'; 'motivo', 'razón de ser', 'objeto'. Y dicho sustantivo se deriva de arguo, -êre, -ui, utum, 'hacer constar', 'dar a conocer', 'manifestar', 'afirmar', 'denunciar'; 'demostrar', 'probar', 'dejar bien claro'; 'demostrar la culpabilidad', 'acusar', 'inculpar'; 'contradecir', 'desmentir', 'refutar', 'convencer de error'. El español argumentar data de principios del siglo XV (Segura, 2003: 56).

Filosofía, retórica y argumentación no existen en sánscrito; pero sí hay filosofía, retórica y argumentación en la India. Como primera prueba, se puede aducir la misma reflexión india sobre esta escisión entre nāman, 'palabra', y rüpa, 'cosa'.

Las posibilidades técnicas y prácticas del pensamiento, en cualquier época, quedan por tanto estrictamente limitadas por el alcance y la riqueza del caudal idiomático disponible: el número y la extensión de los sustantivos, verbos, adjetivos y partículas. La totalidad de este caudal en la filosofía india se designa con el término nāman (en latín nomen, de donde procede la palabra española "nombre"). La sustancia con la cual opera nuestra mente al pensar está formada por este tesoro nominal de ideas. Nāman es el reino interior de los conceptos, que corresponde al reino exterior de las "formas" percibidas, que en sánscrito se llama rūpa, "forma", "figura", "color" (pues no hay forma o figura sin color) (Zimmer, 1965: 32). 


\section{Filosofía india}

Durante mucho tiempo, la ausencia de un término puso en duda la existencia de un concepto para la filosofía en la India. Sin embargo, a partir de la segunda mitad del siglo $\mathrm{XX}$, ha habido una corriente significativa de defensa de lo que otrora pareciera una contradictio in terminis: una filosofía más allá de Grecia. Tal es, por ejemplo, el parecer de Zimmer: "...existe y ha existido en la India algo que realmente es filosofía” (1965: 39); y de Mora: "Podemos resumir diciendo que hoy ya nadie que haya estudiado verdaderamente los textos sánscritos puede afirmar que no existe filosofía en India antigua" (1978: 20).

En esta línea de pensamiento, Tola y Dragonetti (2008) se proponen confutar el prejuicio de que el pensamiento indio no es filosofía per se, sino "algo más". En el que, actualmente, es quizás el trabajo más completo sobre el tema, postulan cuatro tesis para sistematizar sus apreciaciones. Estas conclusiones son el resultado de un análisis comparativo de gran rigor, llevado a cabo sobre la base de una extensa muestra de textos, todos ellos en sus idiomas originales.

1) ...por lo menos hasta el siglo XVII India, por un lado, y Grecia y Europa, por otro lado, reflexionaron muchas veces sobre los mismos temas filosóficos, y de la misma manera (Primera Tesis).

2) (...) en la historia de las filosofías Griega y Europea se encuentran manifestaciones de irracionalidad bajo muchas formas (una de las cuales es las creaciones de la fantasía, la imaginación) tan numerosas como en la historia del Pensamiento de la India (Segunda Tesis).

3) (...) en India sí existió "tal cosa como una Filosofía de la India” (Tercera Tesis).

4) (...) La comparación entre el pensamiento indio y el occidental debe limitarse a confrontar a ambos tal como se manifestaron antes del siglo XVII, o incluso en los siglos siguientes pero, en este caso, cuando ellos mantienen formas que prolongan a las filosofías previas a esa fecha (Cuarta Tesis). (Tola y Dragonetti, 2008: 21-28).
Al enfrentarse a textos filosóficos de ambas tradiciones, llama la atención el hecho de que, no solo aparecen numerosas coincidencias, sino que, en algunas ocasiones, la reflexión india precede a la griega. Mora resalta este aspecto: “...en sus inicios la filosofía hindú sí llega a las mismas interpretaciones a las que llegaría después Occidente, sobre los mismos hechos" (1978: 105, itálica del original). Más aún, llega a hacer una afirmación controversial, al relativizar la condición de Grecia como sitio de origen de la filosofía:

(...) el Rig Veda es trascendental no solamente para la historia de la filosofía en la India, sino para la historia de la filosofía universal, constituyendo, además, el primer documento humano con un contenido filosófico indiscutible que, a mayor abundamiento, plantea ya las observaciones que más tarde serían base de varias importantes corrientes filosóficas en Occidente" (Mora, 1978: 29).

India y Grecia son ramas dentro de la familia indoeuropea, por lo que las coincidencias culturales pueden ser producto, bien de un origen común, bien de contactos posteriores. En materia de contacto cultural, conviene traer a colación las precisiones históricas esbozadas por Rawlinson (1975: 425-441):

1) el primer contacto, documentado, entre India $y$ Grecia ocurrió en el año 510 a.C., cuando Darío envió a un mercenario griego, Escílax de Carianda, a navegar por el Indo;

2) desde la perspectiva griega, se tienen las informaciones de Heródoto, Ctesias y Megástenes;

3) del lado indio, se cuenta con varias menciones, en el Mahābhārata, de los jonios (Yavanas), los escitas (Śakas) y los partos (Pahlavas), todos ellos aliados de los kauravas;

4) durante todo este período, Persia fue el vínculo entre ambas culturas, tanto con tropas indias sirviendo en invasiones a Grecia, como con mercenarios griegos sirviendo en India; y

5) el principal punto de contacto se puede apreciar en el desarrollo de las ideas filosóficas, especialmente por los paralelismos entre el pensamiento de las Upanișadas y los presocráticos, o entre las nuevas agrupaciones (budistas y jainistas) y los círculos órficos y pitagóricos. 
Específicamente, con respecto a la filosofía, existen paralelismos significativos. Para poder determinar las semejanzas y diferencias en el tratamiento de estos temas en cada cultura, conviene utilizar el método comparativo, como lo aconseja la propia escuela Nyāya, la cual incluye el upamāna, 'inferencia por analogía o comparación', como uno de los cuatro pramānas, 'medios del correcto conocimiento'.

Entre las diferencias, cabe destacar, en primer lugar, la dicotomía entre filosofía y teología. Al respecto, afirma Zimmer que “... la filosofía india está mucho más del lado de la religión que el pensamiento crítico y secularizado del Occidente moderno" (1965: 17). No obstante, la primera tesis de Tola y Dragonetti sortea este escollo estableciendo como límite de la comparación el siglo XVII, pues antes de esta fecha la filosofía Occidental también se halla próxima a la religión. No ocurre lo mismo con la filosofía moderna, la cual, claramente, se contrapone a la teología. Esto se evidencia en el plano lingüístico:

\begin{abstract}
(...) La filosofía moderna presupone que la razón humana es el órgano de la verdad en cuanto nos es posible acercarnos a ella. La filosofía habla de evidencia, de intuición: todas metáforas propias de la vista... La teología tradicional presupone que la razón humana es incapaz de llegar a la última verdad, pero que el hombre posee un órgano apto para recibirla: la fe $-\mathrm{y}$ que, en consecuencia, el hombre debe acoger y escuchar esa "revelación". Este conocimiento es lo que caracteriza a lo que más tarde se llamó teología. La palabra teología habla de seguir una llamada, de oír, de escuchar: expresiones todas ellas basadas en metáforas del oído (Panikkar, 2000: 34).
\end{abstract}

En la literatura sánscrita, existe una división fundamental entre Śruti, 'tradición revelada', y Smṛti, 'tradición memorizada'. En cuanto a la Śruti, se considera que la revelación procede de los rșis, 'sabios', quienes vieron los textos que se manifestaban por intervención de la divinidad y, luego, los repitieron para que fueran oídos por las futuras generaciones. Malamoud (2000: 68) ha puesto en evidencia el sistema metafórico implícito en estas imágenes: “nótese la sucesión de metáforas: los ṛșis vieron los Vedas, pero los han legado a las generaciones posteriores bajo la forma de un texto que ha de ser escuchado y repetido". Textos religiosos por excelencia, los Vedas pertenecen a esa Śruti, que, si se parte de la raíz ŚRU, 'escuchar', comparte, con la teología, la metáfora del oído.

Una segunda diferencia se encuentra en la dicotomía entre $\lambda$ ó $\gamma$ os-ratio y $\mu \tilde{v} \theta$ os-fides. Para Zimmer, por un lado, la "filosofía india afirma con insistencia que las experiencias posibles que la mente puede tener con respecto a la realidad exceden en gran medida la esfera del pensamiento lógico" (1965: 33); por otro, la "filosofía occidental carece de doctrina secreta; lanza un reto general para que se examinen sus argumentos, sin pedir otra cosa que inteligencia e imparcialidad en la discusión" (1965: 61).

Así pues, parece ser que la filosofía occidental sería más "lógica", mientras que, a la india, le iría también el calificativo de "mítica". Empero, la división no es tan tajante, como lo pone de manifiesto la segunda de las tesis de Tola y Dragonetti: en ambas tradiciones hay cabida para la irracionalidad. A modo de ejemplo, recuérdese como la obra de Dodds, The Greeks and the Irrational, vino a problematizar los postulados de Nestle, en Vom Mythos zum Logos.

Otras diferencias, en opinión de Matilal (1998: 14-15), se deben a que, en la filosofía india, la lógica va unida a otras disciplinas:

1) la lógica va unida a la epistemología, porque la inferencia es un medio de conocimiento;

2) la lógica va unida a la psicología, dada la causalidad de las series de eventos mentales;

3) la lógica va unida a la gramática, debido a la ordenación fonética, morfológica y sintáctica del sánscrito, cuya estructura, desde la gramática de Pāṇini, posee una precisión matemática; y

4) la lógica no distingue, de manera absoluta, entre deducción e inducción.

Por su parte, como semejanzas se pueden mencionar, siguiendo a Panikkar (2000: 46-55), estas: 

1) ambas poseen un componente fundamentalmente cognoscitivo,
2) ambas se ocupan de la pregunta por la verdad y
3) ambas tienen una función liberadora.

Quid ergo est philosophia Indiae? Es una forma de vidyā, 'sabiduría', 'conocimiento' (Zimmer, 1965: 56), de la raíz VID, 'ver', 'conocer'. Es un método de indagación (Mora, 1978: 18), que puede ser designado como tarka, 'conjetura', 'razonamiento', 'especulación', de la raíz TARK, 'suponer'; como nyāya, 'método', 'regla', de la raíz Nİ, 'conducir'; o como ānvīkșiki, 'indagación', 'filosofía lógica', de la raíz ĪKȘ, 'ver', y el prefijo $a n u$, 'seguidamente'. Es un ámbito de reflexión, como se colige del léxico existente (Mora, 1978: 94): tarkika, 'filósofo', 'dialéctico'; tarkayukta, 'que implica una conjetura', 'que va a la par con el sistema filosófico'; tarkavid, 'conocedor de lógica'; nyāyavidya, 'ciencia de lo correcto', 'lógica'; anumānokti, 'argumento', 'inferencia', 'razonamiento', inter alia.

El filósofo, a su vez, es aquel que incursiona en este camino, mediante la relación tradicional entre guru, 'maestro', y sișya, 'discípulo'. El aprendizaje filosófico se caracteriza por la continuidad, la cual se sustenta en la reciprocidad entre $\varphi \imath \lambda i ́ \alpha$, 'amor', у бoфí $\alpha$, 'sabiduría': "El filósofo, entonces, no es tanto el aprendiz a saberlo todo, como el aspirante a un ideal que aún no se ha alcanzado. El filósofo es amante de la sabiduría porque participa en la sabiduría del amor, y en cuanto tal es filósofo: no ha escindido el amor del saber ni ha subordinado el uno al otro" (Panikkar, 2000: 16). Al respecto, Zimmer (1965) señala lo siguiente:

El filósofo es un hombre cuya naturaleza ha sido transformada, reformada según un modelo de características realmente sobrehumanas, como resultado de haber sido colmado por el mágico poder de la verdad. Por esta razón el futuro discípulo tiene que ser sometido a cuidadosas pruebas. La palabra adhikārin como adjetivo significa, literalmente, "con título para, con derecho a, dotado de autoridad, dotado de poder, calificado, autorizado, adecuado para"; también significa "perteneciente a, poseído por"; y como sustantivo, "oficial, funcionario, jefe, director, justo reclamante, dueño, propietario, personaje calificado para efectuar algún sacrificio u obra piadosa" (Zimmer, 1965: 56).

Quizás el término más próximo a filosofía en sánscrito sea darśana, 'punto de vista', de la raíz DṚŚ, 'señalar'. Esta se compone, en el Hinduismo, de seis escuelas principales:

1) sānikhya, 'cálculo', de sam-KHYĀ, 'estimar': sistema evolucionista basado en veinticinco tattvas, 'principios' (Macdonell, 1968: 345).

2) yoga, 'yoga', de la raíz YUJ, 'unir': sistema dualista que parte de la oposición entre purușa (res cogitans) y prākrti (res extensa) (Agud, 1995: 52).

3) mīmāmssā, 'indagación', de MAN, 'considerar': sistema panteísta que discute principalmente la naturaleza de Brahman, 'alma universal' (Macdonell, 1968: 229).

4) nyāya, 'análisis', de la raíz NĪ, 'conducir': sistema de lógica (Agud, 1995: 52).

5) vaiśeșika, 'características individuales', de $v i$-ŚIȘ, 'distinguir': sistema de física y metafísica (Agud, 1995: 52).

6) vedānta, 'fin de los Vedas': filosofía sistemática desarrollada a partir de las Upanișadas (Agud, 1995: 54).

Empero, hay otras clasificaciones posibles. Por ejemplo, "filosofías del tiempo", que son “... las tres filosofías indias de la vida mundana -el llamado trivarga-: las doctrinas políticas del arthaśāstra, las psicológicas del kāmaśāstra y la ética del dharmaśāstra..." (Zimmer, 1965: 75); y "filosofías de la eternidad": los citados sāinkhya y yoga, pero también el brahmanismo, el jainismo, el budismo y tantrismo.

Tal pluralidad ideológica resulta en que algunos autores opten por descartar el concepto de "filosofía de la India", en favor de uno más amplio: "filosofías de la India" (Mora, 1978: 51). A nuestro juicio, el problema de nāman, 'palabra', seguirá existiendo en la medida en que necesitemos términos occidentales. Pero, más que una aporía, se trata de una encrucijada, como en todos los contactos culturales: "A diferencia de otras disciplinas humanas, la reflexión sobre la naturaleza misma de la filosofía pertenece a la 
propia disciplina. Cada filosofía posee su propia interpretación y, por tanto, una noción propia de lo que ella misma sea" (Panikkar, 2000: 40).

En este mar de corrientes, sobresalen las siguientes afluentes (Tola y Dragonetti, 2008: 57-59):

1) $\operatorname{los}$ Vedas

2) las Upanishads

3) los Maestros del Error (materialistas, amoralistas, atomistas, escépticos, deterministas)

4) el Jainismo

5) el Budismo

6) la Escuela Abhidharmika (Hīnayāna)

7) la Escuela de Nāgārjuna (Mahāyāna)

8) la Escuela Yogācāra (Mahāyāna)

9) la Escuela lógico-epistemológica

10 el Materialismo

11) el Brahmanismo e Hinduismo

12) la Escuela Mìmāmsāa

13) la Escuela Vedānta

14) la Escuela No-dualista de Shankkara (división de la escuela Vedānta)

15) la Escuela No-dualista calificada de Rāmāmuja (división de la escuela Vedānta)

16) la Escuela Dualista de Madhva (división de la escuela Vedānta)

17) la Escuela Sāmkhya

18) la Escuela Yoga

19) la Escuela Nyāya

20) la Escuela Vaisheshika

21) la Filosofía del Lenguaje de Bhartrihari

De ellas, 9 y 19, pero también 4 y 5, son fundamentales para el desarrollo de la lógica india, la cual, a su vez, será básica para el surgimiento de una retórica india. La escuela lógico-epistemológica se ocupó del estudio de los pramānas, 'medios del correcto conocimiento', y de los hetvābhāsas, 'falacias'; la escuela Nyāya, tanto a la lógica como a la epistemología. Por su parte, los budistas contribuyeron con el parārthānumānam, 'silogismo'; y los jainistas, con el anekāntavāda, 'teoría de la no-unilateralidad o multi-lateralidad'.

La lógica constituye uno de los componentes esenciales de la filosofía en la
India. Este hecho se constata en la terminología: nyāya es tanto 'lógica', en particular, como 'filosofía', en general; incluso, puede ser 'retórica' o 'argumentación'. El interés por la lógica en la India puede haber surgido de preocupaciones de índole metafísica (Basham, 1956: 501); de la larga tradición de debates (Matilal, 1998: 2); del diagnóstico médico (Dasgupta); de la ciencia del ritual (Solomon); de la gramática (Staal); de la hermenéutica poética y mitológica (Keith) (todos los últimos citados por Arnau, 2008: 27).

Las escuelas de lógica parten del estudio del proceso de inferencia (Basham, 1956: 501). Esta puede ser svārtha-anumāna, 'inferencia para uno mismo', o parārtha-anumāna, 'inferencia para otro'. En ambos casos, consiste en un proceso de razonamiento. Si se realiza mediante el pensamiento, se trata de una inferencia, pero, si se expresa a través del lenguaje, constituye un argumento (Gillon, 2010: 2). Siempre se describe mediante un argumento de cinco miembros (Mora, 1968: 40-41; Arnau, 2008: 39-40):

1) pratijñā, 'proposición'. E. g., hay fuego en la montaña. Se compone de pakșa, 'sujeto del razonamiento', $i$. e., la montaña; y de sādhya, 'propiedad que se atribuye al sujeto', i. e., el fuego.

2) hetu, 'causa asociada con la propiedad atribuida'. E. g., porque la montaña humea.

3) udāharaṇa, 'ejemplificación'. E. g., donde hay humo hay fuego, como en la cocina, y a diferencia del lago. Se compone de sapakșa, 'ejemplo positivo', i. e., la cocina; y de vipakșa, 'contraejemplo', i. e., el lago.

4) upanaya, 'recapitulación'. E. g., dado que la montaña humea.

5) nigamana, 'conclusión'. E. g., por tanto, hay fuego en la montaña.

Varios autores han puesto en relación este "silogismo indio" con el silogismo aristotélico. Así, el tercer término correspondería a la premisa mayor; el segundo, a la menor; y el tercero, a la conclusión (Basham, 1956: 501). No obstante, el ejemplo constituye una parte esencial del argumento. En términos de lógica, la inferencia puede ser tanto deductiva como 
inductiva (Arnau, 2008: 46), en razón del principio de vyāpti, 'concomitancia invariable' (Basham, 1956: 502). En términos de retórica, no hay una contraposición entre entimema y ejemplo; la argumentación india fusiona ambos procedimientos. Según Basham (1956: 502), el ejemplo confiere fuerza retórica a un argumento; según Arnau (2008: 67), el ejemplo es aquello en lo que están de acuerdo el experto y la persona corriente.

Lloyd profundiza sobre este papel esencial del ejemplo, al afirmar que "pese a que Aristóteles habla de argumentos a partir de ejemplos, claramente los dṛstânta del Nyāya no son como los paradeigma aristotélicos, puesto que, en vez de ofrecer 'evidencia suplementaria', conectan la proposición y la causa" (Lloyd, 2011: 91; traducción del autor). Asimismo, señala lo siguiente: “...El Nyāya combina los dos elementos clave de la retórica de Aristóteles, el entimema y el ejemplo, de una manera única, algo que el propio Aristóteles no predijo. En vez de razonar mediante una cadena de enunciados interrelacionados, el Nyāya desarrolla la idea de que el razonamiento debe basarse en una analogía dominante" (Lloyd, 2011: 77; traducción del autor, itálica del original).

Es, pues, la lógica india una lógica distinta de la aristotélica. Su texto básico es el Nyāya Sūtra. El término sūtra, 'hebra', 'sarta de reglas', 'colección de aforismos', remite a un manual, un libro de reglas (Zimmer, 1965: 42, nota 23). Al Nyāya Sūtra habría que añadirle, para un estudio sistemático de la lógica india, los diversos comentarios que suscitó tras su aparición. Entre los principales (Lloyd, 2011: 79 nota 10 ), se encuentran estos:
1) Vatsāyana: Nyāya Bhāṣya
2) Udyotakara: Nyāya Vārttika (s. VI)
3) Vācaspati Miśra: Nyāyavārttikatātparyațīkā (s. IX)
4) Udayana: Nyāyatātparyapariśuddhi (s. X)
5) Jayanta Bhatta: Nyāyamañjari (s. X)
6) Bhāsavarajña: Nyāyasāra (s. X)

El primer aforismo del Nyāya Sūtra enumera los dieciséis padārthas, 'categorías', en torno a los cuales se estructuraba cualquier tipo de interacción filosófica, retórica o argumentativa (Arnau, 2008: 35-36):
1) pramāṇa, 'medio de conocimiento'
2) prameya, 'objeto a conocer'
3) saṃśaya, 'duda'
4) prayojana, 'propósito'
5) drșțānta, 'ejemplo'
6) siddhānta, 'supuesto'
7) avayana, 'miembro de la inferencia'
8) tarka, 'razonamiento hipotético'
9) nirnaya, 'comprobación'
10) $v \bar{a} d a$, 'discusión constructiva'
11) jalpa, 'discusión tramposa'
12) vitaṇda a , 'argumentación negativa o capciosa'
13) hetvābhāsa, 'falacia'
14) chala, 'palabrería'
15) jāti, 'sofisma'
16) nigraha-sthāna, 'posición derrotada'

No obstante, la lógica, al igual que el resto de la filosofía en India, tuvo desarrollos diversos en el núcleo de cada escuela de pensamiento. Por ejemplo, según la escuela Nyāya, existen cuatro pramānas, 'medios del correcto conocimiento':
1) pratyakșa, 'percepción'
2) anumāna, 'inferencia'
3) upamāma, 'inferencia por analogía o
comparación'
4) śabda, 'palabra'

Pero, con la escuela Vedānta, se añaden dos más: 
5) arthāppati, 'intuición'

6) anupalabdhi, 'no percepción'

También a manera de ejemplo, se puede traer a colación el $s y \bar{a} d v \bar{a} d a$, 'doctrina del quizá', también conocido como saptabhaingi, 'división en siete partes', de acuerdo con el cual, la lógica jainista no acepta como válido el principio del tercero excluido (Basham, 1956: 502), puesto que hay siete aspectos de la predicación:

1) syādasti, 'el objeto es en tanto objeto'

2) syānnāsti, 'el objeto no es tanto otra cosa'

3) syādastināsti, 'el objeto es en cierto sentido y no es en otro sentido'

4) syādavaktavya, 'el objeto es indefinible'

5) syādastivaktavya, 'el objeto es, pero su naturaleza es indefinible'

6) syānnāstyavaktavya, 'el objeto no es, pero su naturaleza es indefinible'

7) syādastināstyavaktavya, 'el objeto es y no es, pero su naturaleza es indefinible'

En síntesis, existen varias escuelas filosóficas en la India. Dentro de ellas, el estudio de la lógica ocupa un lugar primordial. Se trata, por un lado, de una lógica distinta de la aristotélica $\mathrm{y}$, por otro, de una lógica que incorpora, al menos en parte, la retórica.

\section{Retórica india}

El punto de contacto entre lógica $y$ retórica en India, al igual que en Grecia, es la palabra como ámbito de dominio. Vāc, 'Palabra', es una divinidad poderosa (R.V. X, 125), cuya esfera de influencia se extiende a la "actividad" discursiva, al "conocimiento" expresado mediante el lenguaje, y al "propio poder de la palabra" (Niwas, 1971: 1; traducción del autor). Kennedy (1998: 171-190) ha analizado, a partir de esta premisa, la presencia de elementos de naturaleza retórica en la literatura india. Con base en sus apreciaciones, se propone la siguiente clasificación:
1) Retórica védica: persuasión de la divinidad en favor de la comunidad.

2) Retórica brahmánica: táctica de legitimación del sistema de clases.

3) Retórica del discurso en la épica: embajadas en el Udyoga Parvan, 'Libro del esfuerzo', del Mahābhārata; trenos en el Strī Parvan, 'Libro de las mujeres', también del Mahābhārata; asambleas en el Ayodhya Kāṇda, 'Sección de Ayodhya', del Rāmāyaṇa.

4) Retórica del debate en las Upaniṣadas: diálogo en el tercer adhyana, 'capítulo', de la BṛhadAranyaka.

5) Retórica engañosa: debate de los vitandines, 'sofistas'.

6) Retórica budista: estructura de los sermones de Buda.

7) Retórica intercultural: Milinda Panha, relato de las conversaciones entre el rey griego Menandro y un monje budista.

8) Retórica deliberativa: tópicos y figuras retóricas en el Arthaśāstra I, 14; II, 10; XV, 1.

Asimismo, cabría añadir una retórica judicial que contó con un desarrollo considerable:

A defendant's answer was limited to one of four possibilities: denial of the fact; confession; admission of the fact with a plea of mitigating circumstances; or claim that a judgment had been made earlier. Those categories have some resemblance with the stasis theory, determination of the question at issue, as expounded by Greek and Latin writers on judicial rhetoric: fact, legality, quality, and jurisdiction (Kennedy, 1998: 184).

La respuesta de un acusado se limitaba a una de estas cuatro posibilidades: negación del hecho, confesión, admisión del hecho con un alegato de circunstancias atenuantes o aducción de un fallo dado previamente. Estas categorías guardan cierta semejanza con la teoría de la stasis, determinación del asunto en cuestión, tal como la plantearon los escritores griegos y latinos de retórica judicial: hecho, legalidad, cualidad y jurisdicción (Traducción del autor).

Recientemente (Lloyd, 2011: 76; traducción del autor), se ha postulado el nyāya como "la metodología retórica de la India". La 
confrontación de sus planteamientos con los de la retórica griega ha arrojado conclusiones relevantes para los estudios de retórica comparada, por ejemplo, la posible existencia de "universales retóricos": "Este estudio de la Retórica de Aristóteles y los Nyāya Sūtras de Gautama implica que puede haber algunos 'universales' retóricos: razonamiento por fórmulas de proposición/causa; argumentación a partir de ejemplos" (Lloyd, 2011: 104; traducción del autor).

Este análisis comparativo ha identificado los siguientes puntos en común entre la escuela Nyāya y Aristóteles (Lloyd, 2011: 85-86):

1) ambos pueden tener una estructura entimemática bipartita;

2) ambos constituyen métodos inferenciales; y

3) ambos cuentan con recursos deliberativos, al resultar de la interacción entre orador y auditorio.

Con todo, las diferencias no dejan de ser significativas. En primera instancia, el espectro del modelo indio se muestra más amplio: "El propósito de la argumentación en el $N y \bar{a} y a$ siempre es el éxito en la vida. Un proverbio hindú lo expresa de manera muy hermosa: 'El paciente no recupera su salud al escuchar la descripción de la medicina"' (Lloyd, 2011: 92; traducción del autor). Nyāya, entonces, abarca, pero no agota, la dimensión retórica.

En segundo término, nyāya no llega a imponerse como modelo retórico: "Nyāya estaba, para esta época [sc. Imperio Mongol, 1526-1858], firmemente establecido como una de las seis escuelas indias de pensamiento, y todas estas seis escuelas habían adoptado sus métodos de argumentación" (Lloyd, 2011: 97; traducción del autor). En consecuencia, conviene tener en cuenta el aporte de las restantes escuelas de pensamiento a la retórica.

En tercer lugar, nyāya no separa teoría y práctica: "Nyāya también explica cómo el razonamiento práctico puede funcionar en contexto. Al evitar la lógica abstracta de Occidente, el Nyāya nunca separa la teoría de la práctica, y revela cómo podemos no necesitar premisas mayores o garantías para tomar decisiones" (Lloyd, 2007: 381; traducción del autor). El carácter práctico de la retórica es, precisamente, el responsable de su difusión por la India.

Dichas diferencias se deben a una visión muy particular del fenómeno retórico que se tiene en la India, donde la practicidad, la pluralidad y la universalidad de los planteamientos suele ser una constante en los distintos ámbitos del saber. En este sentido, más que establecer paralelismos directos entre retórica india y retórica griega, parece ser que lo más apropiado es establecer un diálogo entre estas dos disciplinas sobre la base del espacio común de intercambio que ofrece la moderna teoría de la argumentación, entendida esta como una retórica en sentido amplio.

Nyaya methods originated in rhetorical concerns regarding debate (katha) and honest discussion (vada). Debate, logic, and rhetoric in India are interrelated. Nyaya's casuistic (case-specific) methods vividly respond to concerns about rhetoric's applicability to practical matters voiced by philosophers Stephen Toulmin and Albert Jonsen. Because Toulmin created a model of reasoning most influential in modern rhetoric, comparing Nyaya methods to his model provides a pertinent entry into Western rhetorical practices (Lloyd, 2007: 365-366).

Los métodos del Nyaya se originaron en preocupaciones retóricas acerca del debate (katha) y la discusión honesta (vada). Debate, lógica y retórica en India están interrelacionados. Los métodos casuísticos (de casos específicos) del Nyaya responden de forma evidente a las preocupaciones sobre la aplicabilidad de la retórica a asuntos prácticos que han expresado los filósofos Stephen Toulmin y Albert Jonson. Como Toulmin creó un modelo de razonamiento muy influyente en la retórica moderna, comparar los métodos de Nyaya a su modelo representa un acercamiento apropiado a las prácticas retóricas occidentales (Traducción del autor).

Nyāya es un concepto polisémico, que no puede limitarse a la única acepción de "retórica". Conviene, además, tener presente la evolución histórica del concepto:

...the term nyāya, often lightly translated as "logic" (or even "syllogism"), has to be considered as having acquired a new distinctive meaning in the classical period, namely, referring to the "proper way" or "right manner" specifically of thinking, and further 
to a "method" or "methodical procedure", namely, of thinking; thus it came to refer to right thinking or methodical thinking, i.e., the process of reasoned thinking or reasoning (Preidendanz, 2010: 58).

...el término nyāya, a menudo traducido descuidadamente como "lógica" (o incluso "silogismo"), debe ser considerado como uno que ha adquirido un significado nuevo y distintivo en el período clásico, primero, relacionado con "la vía apropiada" o "la manera correcta", específicamente, de pensar, y luego con un "método" o un "procedimiento metódico", esto es, de pensar; por tanto, llegó a hacer referencia al pensamiento correcto o pensamiento metódico, i.e., el proceso de pensamiento razonado o razonamiento (Traducción del autor).

Para efectos del presente trabajo, se propone que la retórica india se puede abordar como interrelación de nyāya, por un lado, entendido, no como "lógica", sino como "retórica de la argumentación"; y alañkāra, por otro, entendido, no como "poética", sino como "retórica de las figuras". Este planteamiento merece un desarrollo más detallado.

En India, hubo cinco escuelas de poética (Kane, 1961: 355-391):

1) la Escuela de Rasa, 'emoción estética': "Rasa primero significa 'sabor', 'sazón', 'gusto', 'deleite', pero metafóricamente significa 'la experiencia emocional de la belleza en poesía y drama" (Kane, 1961: 356; traducción del autor).

2) la Escuela de Alañkāra, 'figura retórica': "Su valor residía en su poder para llevar a la saciedad el significado interno que se percibe mediante la iluminación de la experiencia poética, sublimada de todas las propiedades accidentales, única en sí misma y aun así generalizadora para englobar la más alta realidad" (Niwas, 1971: 4; traducción del autor). En las listas antiguas son más de doscientas (Kane, 1961: 375).

3) la Escuela de Rīti, 'dicción': "La escuela de rìti marca un avance significativo con respecto a la escuela de alañkāra. Pese a que no alcanzó la verdadera esencia de la poesía, se le aproximó bastante. En vez de ver las alankkāras como la esencia de la poesía, se centró en las guṇas [sc. propiedades] como esencia" (Kane, 1961: 381; traducción del autor).
4) la Escuela de Vakrokti, 'ornato': "Vakrokti es un modelo chocante de discurso, a menudo basado en śleșa [sc. ambigüedad], y distinto del modo plano, realmente ordinario del discurso" (Kane, 1961: 385; traducción del autor).

5) la Escuela de Dhvani, 'alusión': "La teoría dhvani es solo una extensión de la teoría de rasa. Trasladó la idea de rasa al ámbito de la poesía" (Kane, 1961: 387 ; traducción del autor).

En este contexto, el Alan்kāraśāstra, 'estudio de las figuras retóricas', llega a ser entendido como una poética india (Gerow, 1971: 9). En una clasificación similar a la grecolatina, las alaìkāras, 'figuras retóricas' pueden ser arthālamkāaras, 'figuras de pensamiento', o śabdālamkāras, 'figuras de dicción'. Las principales fuentes para el estudio de las figuras retóricas (Gerow, 1971: 5-6) son estas:

1) Bharata: Nātyaśāstra

2) Bhāmaha: Kāvyālaṃkāra

3) Daṇụin: Kāvyāadarśa

4) Vāmana: Kāvyālaṃkāravṛtti

5) Udbhața: Kāvyālaṃkārasārasaṃgraha

6) Agni Purāṇa

7) Rudrața: Kāvyālaṃkāra

8) Mammața: Kāvyaprakāśa

Estas figuras retóricas se emplean indistintamente en poética y en retórica, pues en India, a diferencia de Grecia, la retórica no se opone a la poética; más bien, ambas disciplinas se complementan:

General as they are, the figures are not specialized in their application. Comparison is inherently neither poetic nor rhetorical: A simile, to use the formal terminology of the Indian poetic, is a statement about two terms (upameya, upamāna 'subject and object of comparison') tending to the explicit point that they share in common property (sādhāranadharma 'tertium') and expressed through use of some adverbial particle indicating likeliness ('like', 'as') (Gerow, 1971: 14).

Generales como son, las figuras no se especializan en su aplicación. La comparación no es 
inherentemente poética ni retórica: un símil, para usar la terminología formal de la poética india, es un enunciado sobre dos términos (upameya, upamāna 'sujeto y objeto de la comparación'), que tienden hacia el punto explícito que comparten como propiedad común (sādhāraṇadharma 'tertium'), y que se expresan mediante el uso de alguna partícula adverbial que indique similitud ('como', 'tal') (Traducción del autor).

Más aún, las figuras retóricas se sustentan en una estructura lógica, dado que, en India, también al contrario a lo que ocurre en Grecia, la retórica no se opone a la lógica; en este caso, también se puede postular una complementariedad: "la poesía emplea las estructuras de la lógica" (Gerow, 1971: 18; traducción del autor). Por tanto, "el uso desviado de la idea, hablando en términos poéticos, solo representa la mitad de la figura; la forma misma, lógica o gramatical en su origen, proporciona el principio de definición" (Gerow, 1971: 21; traducción del autor).

Si las alaìkāras, 'figuras retóricas', son comunes a la retórica, la poética y la lógica, algo parecido sucede con las hetvābhāsas, 'falacias'. Según la Escuela Sincretista (Keith, 1921: 143-152), hay cinco tipos de falacias, los cuales dependen de la corrección del objeto del razonamiento. Dicha corrección se determina a partir de estas cinco condiciones:

1) El objeto debe estar presente en el pakșa, 'sujeto del razonamiento'.

2) El objeto debe estar presente en los sapakṣās, 'ejemplos positivos'.

3) El objeto debe estar ausente en los vipakșās, 'contraejemplos'.

4) El objeto no debe ser bādhita, 'contradicho', por los hechos.

5) El objeto no debe ser contrabalanceado por asatpratipakșa, 'otra prueba'.

A partir del incumplimiento de una o varias de las citadas condiciones, se llega a las siguientes falacias:
1) savyabhicāra, 'discrepante', también denominada anaikāntika, 'indeterminada' o samdigdha, 'dudosa': la conclusión pierde su certeza por una de estas tres causas:

1.1) sādhāraṇa, 'muy general': está presente en los contraejemplos (condición 3).

1.2) asādhāraṇa, 'muy restringida': está ausente en los ejemplos positivos (condición 2).

1.3) anupasamhārin, 'no inclusiva': es propia solo del sujeto (condiciones 2 y 3 ).

2) viruddha, 'contraria': el razonamiento prueba la tesis opuesta de la aducida. Luego, está ausente en los ejemplos positivos (condición 2) y está presente en los contraejemplos (condición 3).

3) asiddha, 'irreal': la inferencia pierde su validez por la irrealidad de uno de estos tres componentes:

3.1) àśrayāsiddha, 'irreal conforme al sustrato': el sujeto no es real (condición 1). 3.2) svarūpāsiddha, 'irreal en sí misma': la causa no está presente en el sujeto (condición 1).

3.3) vyāpyatvāsiddha, 'irreal conforme a la concomitancia': la relación entre objeto y consecuencia no es necesaria (condición 1).

4) satpratipakșa, 'contrabalanceada': existe fuera del sujeto otra causa que prueba lo contrario de la conclusión (condición 5).

5) bādhita, 'contradictoria': existe en el sujeto la negación de la conclusión (condición 4).

Según la clasificación que se siga, es posible hallar otras falacias, algunas de las cuales también cuentan con equivalencias en la tradición greco-latina, por ejemplo: arthaprasanga, 'reductio ad absurdum'; cakra, 'petitiio principii'; anavasthā, 'argumentum ad infinitum'; anyonyāśraya, 'dilema'; àtmāśraya, 'ignoratio elenchi'; cakraka, 'circulus in probando'. 
Finalmente, existe una clasificación de jātis, 'sofismas'. A continuación, se ofrece una lista de ellas tal como aparecen en el Nyāya Sütra (Motilal, 1998: 61-73):

1) sādharmyasama, 'semejanza'

2) vaidharmyasama, 'desemejanza'

3) utkarșasama, 'adición de una propiedad'

4) apakarșasama, 'sustracción de una propiedad'

5) varnyasama, 'incertidumbre'

6) avarnyasama, 'certidumbre'

7) vikalpasama, 'alternancia'

8) sādhyasama, 'duda sobre el ejemplo'

9) prāptisama, 'conexión'

10) aprāptisama, 'desconexión'

11) prasañgasama, 'razón para la razón'

12) pratidrșțāntasama, 'contraejemplo'

13) anutpattisama, 'no-origen'

14) samśayasama, 'duda'

15) prakaraṇasama, 'desequilibrio'

16) ahetusama, 'rechazo de la razón'

17) arthāpattisama, 'presunción'

18) aviśeṣasama, 'no-diferenciación'

19) upapattisama, 'evidencia'

20) upalabdhisama, 'aprehensión'

21) anupalabdhisama, 'no-aprehensión'

22) nityasama, 'no-permanencia'

23) anityasama, 'permanencia'

24) kāryasama, 'efecto'

Alàikāras, 'figuras retóricas'; hetvābhāsas, 'falacias'; y jātis, 'sofismas'; todos estos son temas propios del $\lambda$ ó $\gamma o \varsigma$, 'discurso', por usar la

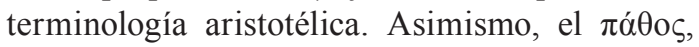
'emociones del auditorio', guarda cierta relación con el planteamiento de estética de la recepción artística esbozado en la teoría del rasa, 'emoción estética', que puede ser śrnigāra, 'erótico'; hāsya, 'cómico'; karuna, 'patético'; raudra, 'furioso'; vīra, 'heroico'; bhayānaka, 'terrible'; bībhatsa, 'odioso'; y adbhuta, 'maravilloso'. Por último, el $\tilde{\eta} \theta$ o $\varsigma$, 'carácter del orador', depende de otras clasificaciones relevantes para el pensamiento indio, como los "fines de la vida": artha, 'lo material'; kāma, 'el amor'; dharma, 'el deber'; y mokșa, 'la liberación'.

Al considerar la retórica greco-latina en su doble dimensión de figuras y argumentación, se puede concluir que el nyāya, 'retórica de la argumentación', indio solo se ocupa de la segunda de estas facetas, mientras que la primera es objeto del Alańkāraśāstra, 'estudio de las figuras retóricas'. Por consiguiente, el estudio de la retórica india ha de abocarse tanto a los esquemas argumentativos determinados por la lógica como a las figuras retóricas introducidas con diferentes propósitos en los textos literarios.

\section{Argumentación india}

En una cultura en que la palabra ostenta un poder sagrado, kathā, 'discusión filosófica', fue una práctica habitual (Arnau, 2008: 51). Hubo tres disciplinas en el arte de la controversia (Arnau, 2008: 52-54):

1) vāda, 'conversación': entre maestro y discípulo, de carácter amistoso, orientado a la verdad, organizado mediante proposiciones contrarias (tesis y antítesis) con la forma de un silogismo.

2) jalpa, 'sofistería': entre escuelas filosóficas rivales, de carácter malintencionado, orientado a la victoria, lleno de trucos (sofismas, falacias, teatralidad, "retórica del miedo"). En este sentido, una "contrarretórica del miedo" sería defendida por los jainistas, quienes introdujeron su concepto de ahims $\bar{a}$, 'no violencia', a la argumentación filosófica (Arnau, 2008: 87).

3) vitandā, 'argumentación capciosa': entre participantes de torneos dialécticos, de carácter competitivo, orientado a la refutación. 
El vitandín, 'ironista', ponía en evidencia las inconsistencias en la argumentación de su oponente, pero sin proponer una tesis propia.

El término sánscrito vitạ̣dă, cuando se dice de una palabra, de una doctrina o de una proposición significa falaz, y tiene una connotación de frivolidad y malicia. Entre sus significados se encuentra el de "crítica ociosa", "objeción capciosa", "controversia frívola o falaz", "crítica capciosa en general"... Cuando se aplica a una réplica en una argumentación o debate el término tiene dos aspectos. El negativo se puede traducir por "capcioso", eso que hace arrancar al contrincante una respuesta que podría comprometerlo o que favorece el propósito del que la formula. En su aspecto positivo significaría "argumentación negativa". El término tiene algo también de burla fina y disimulada y, como en la ironía, de pretensión de dar a entender algo diferente a lo que se dice. Es precisamente esa distinción entre decir y mostrar la que permite leer a los vitandines como ironistas (Arnau, 2008: 54-55).

Esta tradición de argumentación filosófica en India guarda cierta semejanza con lo que acaecía en Grecia en época de Sócrates, Platón y Aristóteles; sin embargo, la temática de los debates difería considerablemente (Matilal, 1998: 31): en Grecia, moral y política; en India, metafísica, principalmente, y moral, solo como consecuencia de la reflexión metafísica. También, se puede establecer, lato sensu, el paralelismo en el nivel léxico: $v \bar{a} d a$, como "debate constructivo", se aproxima a la "dialéctica"; jalpa, como "debate destructivo", a la "erística"; vitanḍā, como "refutación”, al ع̌ $\lambda \varepsilon \gamma \chi 0 \varsigma$ (Matilal, 1998: 56-57).

Actualmente, la argumentación ha sido objeto de un interés creciente en el entorno occidental: Francia, Holanda, Italia, España, Canadá, Estados Unidos, Chile, entre otros. Si bien India no cuenta con grandes representantes en los modernos estudios sobre argumentación, ciertamente posee una larga tradición argumentativa, ejemplificada en la obra del nobel de economía Amartya Sen, El argumentativo indio. $\mathrm{Si}$ a esto se suma el carácter dialógico de la teoría de la argumentación, la cual ha surgido como una nueva retórica, basada en pero nunca limitada a- lo clásico; entonces, esta moderna teoría de la argumentación se muestra un modelo que posibilita el análisis retórico en otros entornos culturales.
Dentro de la literatura sánscrita, la épica se ofrece como un género idóneo para el análisis argumentativo, en razón de la gran cantidad de discursos en estilo directo, narraciones insertadas y hasta debates de índole filosófica que presenta. Por ello, connotados indólogos, como Fitzgerald y Brockington, han investigado sobre aspectos retóricos del Mahābhārata y el Ramāyaṇa, respectivamente.

El Mahābhārata, la gran épica de la India, es la principal fuente del dharma, este concepto transversal del Hinduismo que remite, a un tiempo, al "deber individual", a la "ley social" y al "orden cósmico". Preisendanz (2010: 47; traducción del autor) plantea "que el razonamiento jugó un papel considerable a la hora de determinar el dharma y de llegar a la decisión correcta, y que este contexto pudo entonces haber formado otro contexto intelectual y cultural para el temprano desarrollo de la lógica en la India". Así, si nyāya, 'retórica de la argumentación', es la base para el desarrollo de dharma, 'ley psico-socio-cósmica'; y, si dharma es una constante en el Mahābhārata; luego, este último será una fuente fundamental para el estudio de la argumentación.

En realidad, la argumentación india permeó varias disciplinas:

In a mythological context, methodical thinking (nyāya), not tarka, occurs there on an equal standing with a large number of traditional sciences. These include the Vedas, the auxiliary sciences, the traditional narratives (itihāsa), the teachings relating to government and politics (nītiśāstra), music (ghāndarvaveda), archery or weaponry in general (dhanurgraha), the stories about the deeds of gods and sages (devarșicarita), and medicine (cikitsita) (Preisendanz, 2010: 59).

En un contexto mitológico, el pensamiento metódico (nyāya), no tarka, aparece con la misma frecuencia que una gran cantidad de ciencias tradicionales. Estas incluyen los Vedas, las ciencias auxiliares [sc. śikșā, 'fonética'; kalpa, 'ritual'; vyākaraṇa, 'gramática'; nirukta, 'etimología'; chandas, 'métrica; jyotișa, 'astronomía'], las narrativas tradicionales (itihāsa), las enseñanzas relacionadas con el gobierno y la política (nītiśāstra), la música (ghāndarvaveda), la arquería o la milicia en general (dhanurgraha), las historias sobre los hechos de los dioses y los sabios (devarșicarita) y la medicina (cikitsita) (Traducción del autor). 
Pero entre ellas, la literatura, representada por el Mahābhārata, y la política, objeto del Arthaśāstra, asumen un lugar de primer orden: "un estudio detallado y atento del término y de términos relacionados que se refieran al razonamiento en la épica, especialmente el Mahābhārata, así como en el Arthaśāstra, es necesario para arrojar aún más luz sobre el surgimiento del término nyāya" (Preisendanz, 2010: 60; traducción del autor).

Seguidamente, se incluyen, en atención a estas consideraciones, algunos ejemplos de argumentación extraídos del Mahābhārata.

\section{Ejemplos literarios}

Dos afirmaciones halladas en la bibliografía consultada sirven de punto de partida para la ejemplificación de la teoría precedente:

It is a common rhetorical process in the West to trace examples of enthymematic or formally logical arguments within common texts; searching for evidence of Nyāya's design in Indian arguments proves just as engaging (Lloyd, 2011: 104).

Es un proceso retórico común en Occidente rastrear ejemplos de argumentos etimemáticos o formalmente lógicos en textos ordinarios; buscar evidencia del modelo Nyāya en argumentos indios parece igual de interesante (Traducción del autor).

The Mahäbhärata deserves a detailed rhetorical analysis, which could reveal much about the forms and functions of speech in ancient India, both those reflecting older traditions and those contemporary with the work as we have it (Kennedy, 1998: 176).

El Mahābhārata merece un análisis retórico detallado, el cual podría revelar mucho sobre las formas y funciones del discurso en la India antigua, tanto las que reflejen tradiciones más antiguas como las que sean contemporáneas como el texto tal y como lo tenemos (Traducción del autor).

El primer ejemplo procede del Vana Parvan, 'Libro del Bosque', del Mahābhārata. Este tercer libro relata los doce años de exilio a que son sometidos los pāṇdavas tras perder en el juego de dados. La narración principal incorpora varias interpolaciones, como la de
Nala y Damayantī y la de Sāvitrī y Satyavat. En esta última, la heroína se enfrenta a Yama, el dios de la muerte, para salvar a su esposo. El primero de sus discursos ofrece una versión literaria del parārthānumānam, 'silogismo'.

1) pratijñā, 'proposición': “Donde mi esposo es conducido o donde él mismo va, allí también por mí debo ir" (297.21; traducción del autor). Pakșa, 'sujeto del razonamiento', es el deber de la esposa, en tanto que sādhya, 'propiedad que se atribuye al sujeto', es su inseparabilidad del esposo.

2) hetu, 'causa asociada con la propiedad atribuida': "Este es el dharma eterno" (297.21; traducción del autor). La esposa debe acompañar a su esposo porque esa es la ley.

3) udāharaṇa, 'ejemplificación': "En varias formas, en efecto, quienes se autocontrolan en el bosque observan el dharma, tanto en vivienda como en fatiga. Conociendo el dharma, ejemplifican" (297.24; traducción del autor). Sapakșa, 'ejemplo positivo', son los santones, quienes también cumplen con la ley. No hay vipakșa, 'contraejemplo'.

4) upanaya, 'recapitulación': "Por el dharma de uno, por la opinión de los buenos, todos siempre han seguido esa dirección. En verdad, ni un segundo ni un tercero tampoco se desea" (297.25; traducción del autor). Se retoma la idea de eternidad, mencionada en la causa.

5) nigamana, ‘conclusión': “Por tanto, los buenos han dicho que el dharma es lo primero... por tanto, los buenos han dicho que el dharma es lo primero" (297.24-25; traducción del autor). Falta una segunda conclusión explícita, que debería coincidir con la proposición: si la ley es lo primero, y si la ley establece que la esposa debe acompañar al esposo, esta sería la verdadera conclusión.

Llama la atención el hecho de que la estructura esté incompleta. La explicación de ello sería la misma por la que hallamos en textos de la tradición occidental más entimemas que silogismos: la formulación lógica resulta inadecuada en un contexto comunicativo.

El segundo ejemplo se ha extraído del Udyoga Parvan, 'Libro del Esfuerzo', del Mahābhārata. Corresponde al libro quinto y se centra en los esfuerzos orientados a evitar la guerra entre pāṇḍavas y kauravas que 
resultará en la disolución del mundo. Narración y discurso directo coexisten en un libro con cuatro embajadas: el sacerdote de Draupada; el poeta Sañjaya; el avatar, descenso, Kṛ̣nna; y el sirviente Ulūka. Durante la embajada de Kṛ̦̣na, intervienen varios personajes. En el discurso de Vidura, hay un caso de alaikkāra, 'figura retórica', específicamente un upamā, 'símil'.

\begin{abstract}
"Gandhari y tu padre, los cuales, desprotegidos, vagarán por tu malintencionada protección; muertos sus amigos, muertos sus ministros, como polluelos nacidos del huevo con las alas cortadas" (123. 20-21; traducción del autor).
\end{abstract}

El upameya, 'sujeto de la comparación', son los padres de Duryodhana, el príncipe al que se dirige la embajada. El upamāna, 'objeto de la comparación', son los polluelos, cuyo rasgo característico es la desprotección; esta es, precisamente, la sādhāraṇadharma, 'propiedad compartida'. En adición, se recurre al adverbio eva, 'como', a modo de dyotaka, 'elemento clarificador'.

Al igual que en la épica griega, el símil es la figura retórica más común en la épica sánscrita. Hace posible la interrelación del mundo de los héroes con el mundo ordinario, por lo que muchas veces se recurre al empleo de animales para las comparaciones. Cabe destacar que estas figuras, muchas veces, no funcionan únicamente a modo de ornato literario, sino que cuentan con un valor argumentativo, principalmente al apelar a valores dentro del sistema de creencias presente en el texto. Así, dejar a los padres desprotegidos como polluelos sin alas, constituye una acción indigna de un príncipe, más en una sociedad en que el respeto a los padres reviste tal importancia.

\section{Conclusiones}

Sí hubo en la India antigua algo como la filosofía, la retórica y la argumentación occidentales. Darśana, 'punto de vista' representa la filosofía india; la unión entre nyāya y alañkāras evidencia el desarrollo de las dos vertientes de la retórica india, respectivamente, argumentación y figuras; y kathā se refiere a la argumentación india.

El método comparativo ha permitido, sobre la base de la interpretación de los términos en lengua original, el establecimiento de ciertas relaciones conceptuales en cada una de las disciplinas abordadas. Este tipo de correspondencias podrían ser objeto de mayor precisión, por ejemplo, en un análisis comparativo de figuras retóricas, de falacias o de sofismas, entre la retórica griega, por un lado, y la india, por otro.

Para abordar la argumentación en la India, ha sido preciso, en primera instancia, partir de un nivel más general, como lo es la filosofía, en dirección a uno más específico, como lo es la lógica. En segundo término, se ha debido estudiar la retórica como complemento de la lógica. Finalmente, en este espacio de interacción, ha sido posible ubicar la argumentación. Como se ha visto, resulta más conveniente el abordaje de esta desde la óptica de la moderna teoría de la argumentación.

Para la selección de los ejemplos literarios ha resultado de gran utilidad el Mahābhārata, puesto que este texto, como fuente del dharma, 'deber', 'ley', 'orden', ha recibido influencia de la lógica, la retórica y la argumentación indias durante su largo proceso de composición. Retórica de la argumentación y retórica de las figuras se encuentran representadas en la gran épica de la India, de manera particular en el libro $\mathrm{V}$, cuyos discursos de embajada funcionan como espacio idóneo para el empleo de la argumentación.

\section{Bibliografía}

Agud, Ana. 1995. Pensamiento y cultura en la antigua India. Madrid: Akal.

Arnau, Juan. 2008. Arte de probar. Ironía y lógica en la India antigua. México: FCE.

Bailly, Anatole. 2000. Dictionnaire Grec-Français. Paris: Hachette. 
Basham, Arthur. 1956. The Wonder that Was India. London: Sidgwick and Jackson.

Gerow, Edwin. 1971. A Glossary of Indian Figures of Speech. The Haghe: Mouton.

Gillon, Brendan. 2010. "Logic in Early Classical India: An Overview". In Brendan Gillon (ed.) Logic in Earliest Classical India. Papers of the 12th World Sanskrit Conference. Vol. 10.2. Delhi: Motilal Banarsidass.

Kane, P. 1961. A History of Sanskrit Poetics. Delhi: Motilal Banarsidass.

Keith, Arthur. 1921. Indian Logic and Atomism. Oxford: Clarendon Press.

Kennedy, George. 1998. Comparative Rhetoric. New York: Oxford University Press.

Lloyd, Keith. 2007. Rethinking Rhetoric from an Indian Perspective: Implications in the Nyaya Sutra. Rhetoric Review VI(24): 365-384.

Lloyd, Keith. 2011. Culture and Rhetorical Patterns: Mining the Rich Relations Between Aristotle's Enthymeme and Example and India's Nyāya Method. Rhetorica XXIX(1): 76-105.

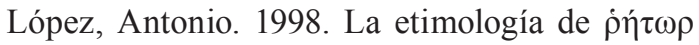
y los orígenes de la retórica. Faventia $\mathrm{XX}(2)$ : 61-69.

Macdonell, Arthur. 1965. A Practical Sanskrit Dictionary. Oxford: Oxford University Press.
Malamoud, Charles. 2000. "La India védica. Religión y mitología". En Raimon Panikkar y Jaume Pòrtulas (eds.) Diccionario de las mitologías. Vol. V. Las mitologías de Asia. Barcelona: Destino.

Mora, Juan de. 1968. La filosofía en la literatura sánscrita. México: UNAM.

Mora, Juan de. 1978. La dialéctica en el Rig Veda. México: Diana.

Motilal, Bimal. 1998. The Character of Logic in India. New York: State University of New York Press.

Niwas, Vidya. 1971. Sanskrit Rhetoric and Poetic. Mahfil VII(3/4): 1-18.

Panikkar, Raimon. 2000. La experiencia filosófica de la India. Madrid: Trotta.

Preisendanz, Karin. 2010. "Reasoning as a Science, its Role in the Early Dharma Literature, and the Emergence of the Term nyāya". In Brendan Gillon (ed.) Logic in Earliest Classical India. Papers of the 12th World Sanskrit Conference. Vol. 10.2. Delhi: Motilal Banarsidass.

Rawlinson, H. 1975. "Early Contacts Between Greece and India" In Arthur Basham (ed.) A cultural History of India. Delhi: Oxford University Press.

Segura, Santiago. 2003. Nuevo diccionario etimológico latín-español y de las voces derivadas. Bilbao: Universidad de Deusto. 
Tola, Fernando y Carmen Dragonetti. 2008. Filosofía de la India. Del Veda al Vedānta. El sistema Sāmkhya. El mito de la oposición entre "pensamiento" indio $y$ "filosofía" occidental. Barcelona: Kairós.
Watkins, Calvert. 2000. The American Heritage Dictionary of Indo-European Roots. Boston: Houghton Mifflin Company.

Zimmer, Heinrich. 1965. Filosofías de la India. Buenos Aires: EUDEBA. 
